\title{
Pengaruh Latihan Passing Menggunakan Media Ban Bekas Terhadap Ketepataan Chest Pass Pada Team Pra PORPROV Kabupaten Kepahiang
}

\section{The Effect Of Passing Training Using Used Tire Media On The Tightness Of The Chest Pass On The Kepahiang District Pre-Prov Basketball Team}

\author{
Veri Rahmat Utama ${ }^{1}$, Dian Pujianto ${ }^{2}$, Ari Sutisyana ${ }^{3}$ \\ ${ }^{1,2,3}$ Pendidikan Jasmani, Universitas Bengkulu JL W.R. Supratman, Bengkulu, 38371, Indonesia
}

\begin{abstract}
Abstrak
Tujuan Penelitian ini untuk mengetahui pengaruh latihan passing dengan media ban bekas terhadap ketepatan chest pass pada tim bola basket pra-porprov kabupaten kepahiang. Metode yang digunakan dalam penelitian ini yaitu dengan Desain pretestposttest one group design. Variabel bebas adalah latihan passing dengan menggunakan media ban bekas variabel terikat adaIah ketepatan Chest Pass, populasi dan sampel adalah tim bola basket pra-porprov kabupaten kepahiang yang berjumlah 13 pria dan 17 wanita, Teknik pengumpulan data penelitian dilakukan tes dan pengukuran. Proses penelitian diawali dengan memberikan pemanasan kepada peserta dan memberikan petunjuk tentang pelaksanaan tes, Data analisis dengan menggunakan statistic uji T. Hasil penelitian menunjukkan, > ruter maka Ha diterima dan Ho ditolak. Dengan demikian Ha dapat diajukan dapat diterima. Temuan dalam penelitian penelitian ini bahwa Iatihan passing dengan media ban bekas dapat digunakan ImpIikasi dari sebagai salah satu jenis latihan untuk meningkatkan hasil ketepatan chest pass bola basket.
\end{abstract}

Kata Kunci : bola basket, chest pass,passing dengan media ban bekas

\begin{abstract}
The purpose of this study was to determine the effect of passing training with used tire media on the accuracy of the chest pass in the Kepahiang district pre-porprov basketball team. The method used in this research is the pretest-posttest one group design. The independent variable is the passing exercise using used tire media, the dependent variable is the accuracy of the chest pass, the population and the sample are the preporprov basketball team in Kepahiang district, amounting to 13 men and 17 women. The research data collection techniques were carried out by tests and measurements. The research process begins with warming up to the participants and providing instructions on the implementation of the test. The data is analyzed using the T test statistic. The results show, > router then Ha is accepted and Ho is rejected. Thus Ha can be submitted can be accepted. The findings in this research study that the passing training with used tire media can be used as a type of exercise to improve the results of the accuracy of basketball chest passes
\end{abstract}

Keywords: Basketball, Chest Pass, Passing

Correspondence author: Universitas Bengkulu, Indonesia.

Email: gymnastics.penjas@unib.ac.id 


\section{PENDAHULUAN}

Permainan bola basket termasuk olahraga yang di gemari oleh masyarakat menyatakan, permainan bola basket adalah olahraga yang menyenangkan, kompetitif, mendidik, menghibur dan menyehatkan serta memiliki keterampilan perseorangan yang cukup sulit sehingga harus latihan dengan rutin agar berhasil dalam memainkannya (Yarmani, 2017).

Bola basket adalah permainan tim dimana anda dapat membantu tim anda dengan meningkatkan keterampilan pribadi anda. Bola basket membutuhkan integrasi bakat individu menjadi tim yang bermain tidak hanya sendiri. Bola basket merupakan olahraga berselang yang menggabungkan perubahan cepat dan berulang-ulang dalam arah gerakan (Iqroni, 2017). Basket itu sendiri pada dasarnya merupakan cabang olahraga permainan yang melibatkan kerjasama dalam sebuah tim. Bola basket sangat cocok untuk ditonton karena biasa dimainkan di dalam ruangan maupun luar ruangan olahraga tertutup dan hanya memerlukan lapangan yang relatif kecil. Selain itu, permainan bola basket juga lebih kompetitif karena tempo permainan yang cepat (Pamuji, 2013).

Menurut PB. PERBASI (2008), ada 3 teknik dasar dalam bola basket yaitu operan (passing), dribling, tembakan ( shooting). Salah satu teknik yang harus di miliki seorang pemain adaIah teknik passing, karena pada zaman sekarang bola basket modern saat ini teknik passing merupakan teknik yang paling berbahaya untuk mencetak angka. Passing memiliki peran yang sangat penting untuk membuat sebuah tim mendapatkan poin. Memasukkan bola ke keranjang musuh akan dapat diIakukan dengan cepat jika didukung passing yang cermat serta tangkapan yang baik. Dengan passing yang cermat serta tangkapan yang baik akan Iebih efisien memindahkan bola untuk berikutnya memasukkan bola ke jaring lawan, dibandingkan dengan teknik dribbIe (Junaidi, 2018).

Salah satu teknik operan yang sering digunakan untuk mengamankan boIa adaIah operan dada (chest pass) Chest pass ialah membegikan boIa ke pada rekan satu tim dengan cara meIakukan passing yang arahnya tepat ke depan dada. Jenis operan ini lebih cepat dan lebih kuat untuk mencapai rekan satu tim yang menjadi sasaran untuk menangkap bola. Pada saat meIakukan chest pass ada beberapa urutan teknik yaitu; (a) Cara memegang BoIa, (b) AwaIan, (c) Tolak 
atau lemparan, (d) Gerakan lanjut, dan (e) Menerima Bola. Teknik chess pass dalam permainan bola basket, akurasi yang baik, yaitu menggunakan dorongan tangan antara otot bahu dengan otot lengan (MeirizaI \& Rusmana, 2018).

Berdasarkan hasil observasi yang telah di lakukan pada tim PraPORPROV belum mempunyai kesiapan alat yang praktis dan inventif untuk mempan dalam melakukan latihan tentang ketepatan chest pass dan pada saat pertandingan maupun latihan pada tim bola basket Pra-PORPROV, dari permainan bola basket terutama tim Pra-PORPROV masih banyak mebuat tindakan kesalahan pada saat passing chest pass, umumnya setiap atlet pada saat melaksanakan chest pass bola yang dipassing tidak terarah kepada teman satu tim atau salah target. KesaIahan dalam melakukan chest pass sangatlah berdampak buruk bagi tim, karena dalam melakukan serangan untuk mencetak angka apabila chest pass yang dilakukan salah target akan mengakitbatkan bola mudah di ambil oleh lawan serta bola sering keluar lapangan sehingga pemilikan bola akan berpindah oleh lawan. Faktor rendahnya saat melakukan passing merupakan rendahnya tingkat akurasi saat melakukan chest pass. Permasalahan-permasalahan tersebut perlu dievaluasi untuk mengatahui sejauh mana keberhasilan program yang telah dilaksanakan (Raibowo \& Nipoyanto, 2020).

Hasil observasi yang telah dilakukan peneliti bahwa teknik dasar bola basket terutama chest pass pada tim Pra-PORPROV masih perlu melakukan peningkatan agar menjadi lebih baik Iagi. Untuk para atlet lebih tetarik pada teknik dasar passing maka diberikan teori melalui aktivitas fisik dengan media ban bekas untuk melatih chest pass sehingga kegiatan latihan akan Iebih menyenangkan bagi tim bola basket Pra-PORPROV. Maka dari itu pengunaan media ban bekas ini bermaksud untuk melihat perbedaan karakteristik, minat bakat para atlet. Penerapan media ban bekas ini sebelumnya sudah direncanakan terlebih dahulu sehingga bisa memecahkan kesalahan dalam melakukan kemampuan chest pass. Media ban bekas tersebut berdampak untuk pengembangan daIam pola latihan yang lebik baik, produktif dan inovatif.

Dalam permasalahan yang ada peneliti ingin memecahkan masalah tersebut dengan solusi chest pass menggunakan media ban bekas. Karena pada prinsipnya untuk mendapatkan akurasi yang baik harusIah memilki target. Iatihan 
menggunakan media ban bekas yang bertujuan agar para atlet lebih aktif dalam melaksanakan latihan, sehingga keterampilan chest pass akan lebih berkembang sehingga akan menjadi lebih baik. Oleh karena itu peneliti ingin memberikan bentuk latihan yang menggunakan media ban bekas untuk mengembangkan keterampilan passing khususnya pada teknik chest pass. Maksud penjelasan diatas dan berkaitan dengan mengembangkan akurasi keterampilan chest pass daIam olahraga basket, maka menjadi penting untuk mengetahui pengaruh yang timbul dari media ban bekas. Sehingga peneliti tertarik untuk melaksanakan penelitian dengan judul "Pengaruh latihan passing menggunakan media ban bekas terhadap ketepatan chest Pass pada tim bola basket Pra-PORPROV kabupaten kepahiang.

\section{METODE}

Jenis penelitian yang digunakan adalah quasi eksperimen. Penelitian eksprimen diartikan sebagai pendekatan penelitian kuantitatif yang paling penuh, artinya memenuhui semua persyaratan untuk menguji hubungan sebab akibat. Metode penelitian eksprimen diartikan sebagai metode penelitain yang digunakan untuk mencari pengaruh pelakuan tertentu terhadap yang lain dalam kondisi yang terkendali. (Sugiyono, 2012: 111). Populasi dalam penelitian ini adalah TIM basket Pra-PORPROV Kabupaten Kepahiang yang berjumlah 30 0rang (17 lakilaki dan 13 prempuan).

Instrumen penelitian adaIah suatu alat yang digunakan mengukur fenomena alam maupun sosial yang diamati ,secara spesifik semua fenomena ini disebut variable penelitian. (Sugiyono,2012). Instrument yang akan digunakan untuk mengumpulkan data adaIah tes AAHPERD passing test dari buku Assessing Sport Skill (Strand,Bradford N. \& WiIson,RoIayne, 1993) dengan tingkat vaIiditas 0,65-0,95 dan reliabilitas 0,84-0,97. Tes ini dilakukan bertujuan untuk mengukur kemampuan chest pass bola basket.

Metode pengambilan keputusan yang didasarkan dari analisis data, baik dari percobaan yang terkontrol, maupun dari observasi (tidak tekonrol). Bila data yang diperoleh berdistribusi normal dan homogen, maka digunakan statistik uji t, dengan rumus 


$$
\mathrm{T}=\frac{M d}{\sqrt{\frac{\sum X^{2} d}{N(N-1)}}} \quad(\text { Suharsimi,2013) }
$$

Keterangan :

$\mathrm{Md}=$ Mean dari perbedaan pretest dan posttest (post tes- pre test)

$\mathrm{N}=$ subjek pada sampel

$\sum^{\mathrm{x} 2} \mathrm{~d}=$ jumlah kuadrat deviasi

$\mathrm{Xd}=$ deviasi masing-masing subjek $(\mathrm{d}-\mathrm{Md})$

d.b. = ditentukan dengan $\mathrm{N}-1$

Menggunakan taraf signifikansi (t table) 5\%

- Hasil penelitian berpengaruh jika thitung $>$ dari t table

- Hasil penelitian tidak berpengaruh jika $\mathrm{t}$ hitung $<$ dari $\mathrm{t}$ table

(Suharsimi,2013)

\section{HASIL}

\section{Hasil Data Pretest Tes AAHPERD}

Hasil pretest pada atlet yang mengikuti Tim PRA PORPROV dan setelah diberikan arahan berupa latihan passing menggunakan media ban bekas seIama 4 minggu dengan frekuensi latihan 4 kali seminggu setelah itu dilaksanakan tes akhir atau posttest untuk mengtahuai ada atau tidaknya peningkatan setelah diberikan arahan, berikut ini adaIah hasil pretest. Dari pretest yang telah dilakukan pada tanggaI 1 september - 1 Oktober 2020 memiliki hasil : a. memiliki hasil tertinggi adaIah 56. b. memiliki hasil terendah adalah 35. c. Rata-rata tes AAHPERD sebesar 46,76

TabeI 1. Daftar distribusi hasii tes AAHPERD (pretest)

\begin{tabular}{|c|c|c|c|c|c|}
\hline Interval KeIas & Frekuensi (f) & NiIai Tengah (x) & $\mathrm{x}^{2}$ & fi.xi & fi. $x i^{2}$ \\
\hline $35-38$ & 5 & 36,5 & 1332.25 & 182,5 & 33306,25 \\
\hline $39-42$ & 3 & 40,5 & 1640.25 & 121,5 & 14762,25 \\
\hline $43-46$ & 7 & 44,5 & 1980.25 & 311,5 & 97032,25 \\
\hline $47-50$ & 5 & 48,5 & 2352.25 & 242,5 & 58806,25 \\
\hline $51-54$ & 5 & 52,5 & 2756.25 & 265,5 & 68906.25 \\
\hline $55-58$ & 5 & 56,5 & 3192.25 & 282.5 & 79806.25 \\
\hline JumIah & 30 & 279 & 13253.5 & 1403 & 352619.5 \\
\hline
\end{tabular}

Berdasarkan tabel tersebut dapat kita ketahui bahwa frekuensinya berjumlah 30, jumlah nilai tengah (x) 279, jumlah $x^{2} 13253,5$, jumlah fi.xi 
Veri Rahmat Utama, Dian Pujianto, Ari Sutisyana

Pengaruh Latihan Passing Menggunakan Media Ban Bekas Terhadap Ketepatan Chest pass Pada

Team Pra Poprov Kabupaten Kepahiang

sebesar 1403 dan jumlah fi.xi ${ }^{2}$ yaitu 352619.5. Berdasarkan tabel tersebut, dapat kita gambar kan dalam sebuah histogram sebagai berikut :

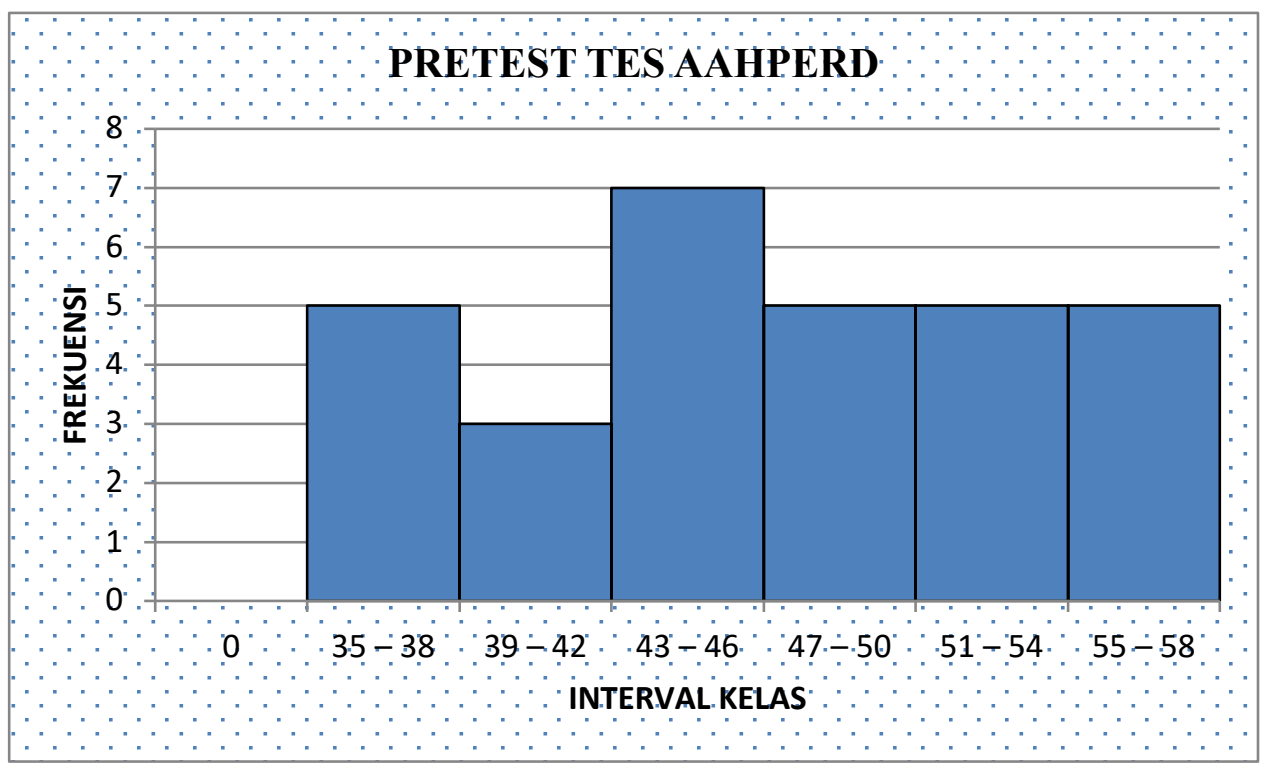

Gambar 1. Histogram Pretest Melempar dan Menangkap Bola

\section{Hasil Posttest ketepatan ChestPass Pada Team Pra-Porprov Kabupaten}

\section{Kepahiang}

Berdasarkan latihan selama empat minggu, memiliki peningkatan hasil chest pass, di bawah ini adaIah hasil posttest daIam bentuk data frekuensi dan histogram. Hasil posttest yang teIah dilakukan pada tanggaI 1 Oktober 2020 untuk keIompok eksperimen diperoleh hasil :

TabeI 2. Daftar Distribusi Hasil TES AAHPERD (Posttest)

\begin{tabular}{cccccc}
\hline Interval KeIas & Frekuensi (f) & $\begin{array}{c}\text { Nilai Tengah } \\
(\mathrm{x})\end{array}$ & $\mathrm{x}^{2}$ & fi.xi & fi.xi $^{2}$ \\
& & & & & \\
\hline $38-41$ & 5 & 39,5 & 1560,25 & 197,5 & 39006,25 \\
$42-45$ & 3 & 43,5 & 1892,25 & 130,5 & 17030,25 \\
$46-49$ & 5 & 47,5 & 2256,25 & 237,5 & 56406,25 \\
$50-53$ & 8 & 51,5 & 2652,25 & 412 & 169744 \\
$54-57$ & 5 & 55,5 & 3080,25 & 277.5 & 77006.25 \\
$58-61$ & 4 & 59,5 & 3540.25 & 238 & 5644 \\
JumIah & 30 & 297 & 14981.5 & 1493 & 415837 \\
\hline
\end{tabular}


Berdasarkan hasil tabel 2. dapat diketahui bahwa frekuensinya berjumIah 30, jumlah nilai tengah (x) 297 , jumlah $x^{2}$ 14981.5, jumlah f.x sebesar 1493 dan jumlah f. $x^{2}$ yaitu 415837. Maka didapat siswa yang mendapatkan nilai antara 38$41=5$ orang, nilai $42-45=3$ orang, nilai $46-49=5$ orang, nilai 50-53 = 8 orang, 54-57 $=5$ orang, 58-61 $=4$ orang. Sehingga didapat nilai rata-rata adaIah 49.76, modus adaIah 47,5 dan kemiringan kurva adaIah 0,020

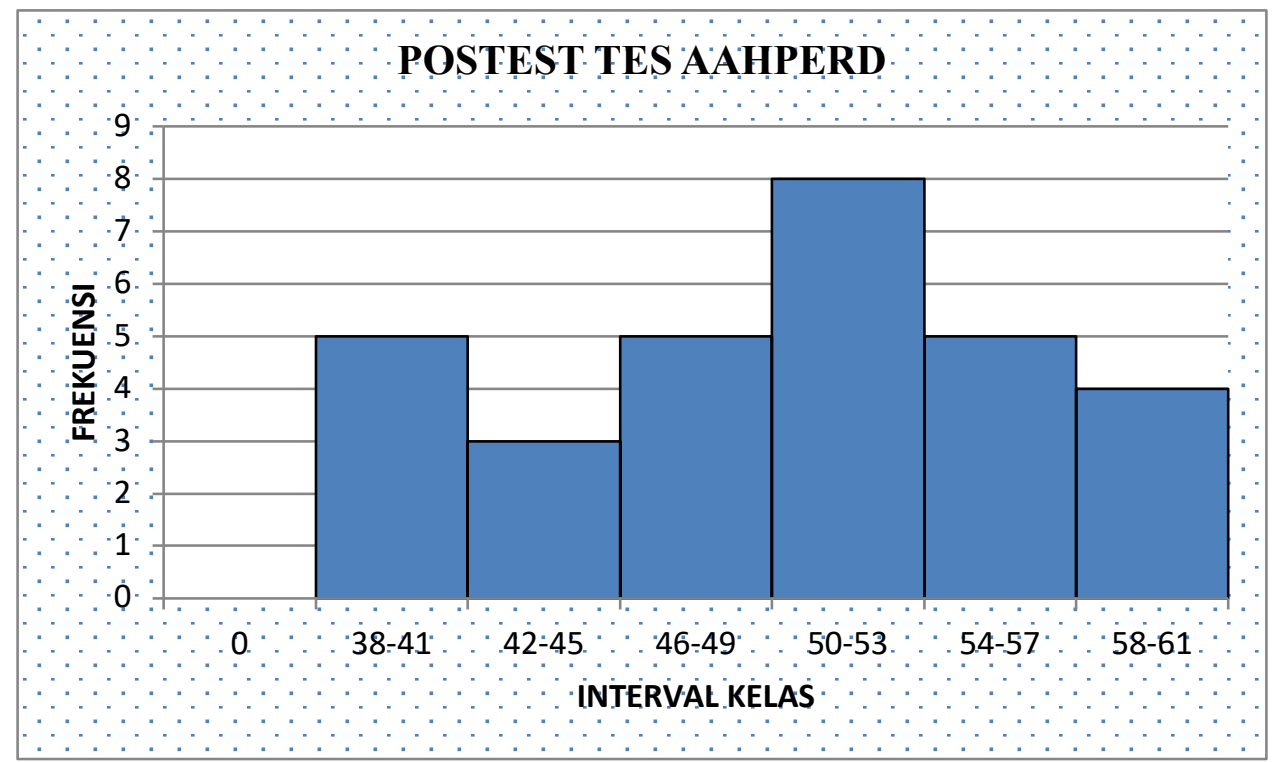

Gambar 2. Histogram Post Test_Melempar dan Menangkap BoIa.

\section{Deskripsi Data Peningkatan Pretest dan Postest latihan Passing Dengan} Media Ban Bekas Terhadap Ketepatan Chest Pass Pada Team Bola Bakset PRA PORPROV Kabupaten Kepahiang

Hasil data pretest tes AAHPERD dengan nilai tertinggi 56 dan nilai terendah 35, dengan rata-rata 47,03, modus 37,14, standar deviasi 99,48 dengan kemiringan kurva 0,096, sedangkan data posttest kelompok eksperimen dengan nilai tertinggi 59 dan nilai terendah 38, dengan rata-rata 49.76 modus 47,5, standar deviasi 108,52 dengan kemiringan kurva 0,020.

\section{PEMBAHASAN}

\section{Pembahasan Hasil Data Pretest Tes AAHPERD}

Berdasarkan hasil data pretest kelompok eksperimen tertinggi 56 dan hasil terendah 35, dengan mean sebesar 46,76, modus data pretest 37,14 serta 
simpangan deviasi yaitu 99,48 dan kemiringan kurva 0,096. Data hasil posstest tertinggi 59 dan hasil terendah 38, dengan mean 49,76, modus data posttest 47,5 serta simpangan deviasi yaitu 108,52 dengan kemiringan kurva -0,020.

\section{Pembahasan HasiI Data Posttest Tes AAHPERD}

Data hasil posstest tertinggi 59 dan hasil terendah 38, dengan mean 49,76, modus data posttest 47,5 serta simpangan deviasi yaitu 108,52 dengan kemiringan kurva -0,020. Berdasarkan penelitian bahwa latihan pengaruh latihan Passing menggunakan media ban bekas terhadap ketepatan Chest pass pada TIM bola basket PRA PORPROV Kabupaten Kepahiang dalam kriteria. Berdasarkan penelitian bahwa latihan pengaruh Passing menggunakan media ban bekas terhadap ketepatan Chest pass pada TIM bola basket PRA PORPROV Kabupaten Kepahiang dalam kriteria sebagai berikut : HaI ini dapat dilihat dari adanya perbedaan antara pretest dan posttest tes AAHPERD setelah diberi perlakuan latihan Passing menggunakan media ban.

\section{Pembahasan Hasil Data Pengaruh latihan Passing Dengan Media Ban Bekas Terhadap Ketepatan Chest Pass pada Team bola basket PRA PORPROV Kabupten Kepahiang}

Berdasarkan latihan yang digunakan untuk meningkatkan Ketepatan chest pass adalah menggunakan latihan passing menggunakan media ban bekas,. Salah satu tindakan yang dapat dilakukan untuk meningkatkan hasil belajar Passing Chest pass yaitu melalui media ban bekas yang dapat membantu atlet dalam melakukan pembelajaran permainan bola basket. Pelaksanaan penggunaan media ban bekas dapat diterapkan dengan mengembangkan gerak dasar Chest pass pada siswa melalui pendekatan bermain bola basket (Ali, 2018). Setiap beban latihan yang diberikan memberikan dampak yang berbeda-beda terhadap struktur otot dalam menyimpan kalori sekaligus memberikan dukungan kinerja fisik. Semakin tinggi cadangan kalori di dalam otot, maka akan semakin besar pula energy yang dikeluarkan oleh tubuh, besarny energy yang dimiliki akan memeberikan kontribusi yang besar terhadap pencapaian optimal (Akhmad, 2015). Menurut Wiguna (2017) latihan merupakan aktivitas jasmani atau olahraga yang telah ditentukan tujuannya, dirancang secara detail dan bertahap untuk penyesuaian perkembangan fisiologi dan psikologi. Maksudnya, dalam suatu latihan yang dilakukan akan memberikan manfaat bagi yang melakukannya baik 
pengoptimalan prestasi dan penampilan olahraga. Prinsip latihan merupakan hal hal yang harus ditaati, dilakukan atau dihindari agar tujuan latihan dapat tercapai sesuai dengan yang diharapkan. Prinsip-prinsip latihan memiliki peranan penting terhadap aspek fisiologis dan psikologis atlet. Beberapa faktor psikologis yang harus diperhatikan oleh pelatih adalah mengenai motivasi, kepercayaan diri, kontrol kecemasan, persiapan mental, pentingnya tim, dan konsentrasi (Nopiyanto, Dimyati, \& Dongoran, 2019).

Dengan memahami prinsip-prinsip latihan, akan mendukung upaya dalam meningkatkan kualitas latihan serta menambahkan minat latihan. Minat ini merupakan perhatian yang mengandung unsur-unsur perasaan Minat ini merupakan dorongan atau keinginan dalam diri seseorang pada objek tertentu. Contohnya seperti, minat terhadap pelajaran, olahraga, atau juga hobi. Minat memiliki sifat pribadi (individual). Artinya, tiap-tiap orang memiliki minat yang dapat saja berbeda dengan minat orang lain. Minat tersebut berhubungan erat dengan motivasi seseorang, sesuatu yang dipelajari. dan juga dapat berubah-ubah tergantung pada kebutuhan, pengalaman, serta juga mode yang sedang trend, bukan bawaan sejak lahir. Faktor yang mempengaruhi munculnya minat seseorang tergantung pada kebutuhan fisik, sosial, emosi, dan juga pengalaman serta memberikan motivasi motivasi sangatlah penting bagi atlet dikarenakan motivasi adalah serangkaian daya penggerakan dalam diri sesorang yang menimbulkan kegiatan berlatih memberihkan arahan pada kegiatan latihan (Nopiyanto \& Raibowo, 2020).

Menurut Lutan dalam Husdarta (2011) tujuan menggunakan media ban bekas dalam pendidikan jasmani yaitu agar: 1) atlet memperoleh kepuasan dalam mengikuti latihan, 2) meningkatkan kemungkinan keberhasilan dalam berpartisipasi, dan 3) atlet dapat melakukan pola gerak secara benar. Menurut Abang Ajiansyah, dkk (2018) Untuk membuktikan apakah media ban bekas dapat mengoptimalkan latihan kemampuan gerak dasar atlet, maka perlu dibuktikan melalui penelitian. Dengan kata lain bahwa alat yang di gunakan dapat juga mempunyai pengaruh besar terhadap keberhasilan sebuah tujuan yang ingin dicapai. Maka sesuai penelitian yang telah dilakukan mengatakan bahwa ada nya 
pengaruh setelah menggunakan media ban bekas untuk digunakan dalam latihan Passing chest pass.

Proses latihan kondisi fisik yang dilakukan secara cermat, berulang-ulang dengan meningkatkan beban latihannya memungkinkan kesegaran jasmani seseorang kian terampil, kuat dan efesien gerakannya. Penelitian ini termasuk penelitian populasi, dikarenakan popuIasi peneIitian 30 atlet, sehingga untuk sampel peneIitian ini peneliti mengambil 13 atlet putra dan 17 atlet putri. Maka penelitian menetapkan sampel untuk penelitian ini berjumIah 30 atlet sebagai kelompok eksperimen. Kelompok ini diberikan perlakuan berupa latihan passing dengan mengunakan ban seIama 4 minggu dengan frekuensi latihan 4 kali seminggu, setelah 4 minggu latihan kelompok penelitian dilakukan tes akhir atau posttest. Dari nilai kemiringan kurva untuk data pretest kelompok eksperimen adaIah 0,096 dan kemiringan kurva untuk data posttest kelompok eksperimen adaIah 0,020. Berdasarkan nilai-nilai tersebut, maka baik pada saat pretest maupun posttest data berdistribusi normal, karena terletak antara (-1) dan (+1).

Jadi dapat disimpulkan bahwa metode latihan Passing menggunakan media ban bekas ini sangat efektif untuk meningkatkan hasil ketepatan chest pass. Dengan demikian maka " adakah pengaruh latihan Passing menggunakan media ban bekas terhadap ketepatan Chest pass pada TIM bola basket PRA PORPROV Kabupaten Kepahiang.

\section{KESIMPULAN}

Berdasarkan hasil penelitian yang yang diperoleh dari penelitian ini dapat disimpulkan sebagai berikut :

1. Berdasarkan hasil penelitian dan pembahasan yang telah diuraikan pada bab sebelumnya, maka dapat disimpulkan Tim pra-porprov Kabupaten Kepahiang mendapatkan nilai pretest dengan nilai rata rata 46,76, serta nilai $\mathrm{Km}$ sebesar 0,096

2. Tim pra-porprov Kabupaten Kepahiang mendapatkan nilai posttes dengan nilai rata rata 49,76, serta nilai $\mathrm{Km}$ sebesar 0,020

3. Mendapatkan pengaruh latihan Passing mengunakan media ban bekas terhadap ketepataan Chest pass pada TIM bola basket pra-porprov kabupaten kepahiang 


\section{REFERENSI}

Ahmad, N., \& Puspitaningsari, M., (2017). Pengaruh Model Pelatihan Machine Gun Pass Terhadap Keterampilan Passing Pada Permainan Bola Basket Tri Darma Jombang. BRAVO'S Jurnal Physical Education And Health Study Program Of STKIP PGRI Jombang. Volume 1 Nomor 3

Ajiansyah, A., Haetami, M., \& Triansyah, A., "Pengaruh Media Bantu Ban Terhadap Hasil Shooting Futsal Pada Peserta Didik Mts Negeri 1 Pontianak. Jurnal Pendidikan dan Pembelajaran ,7(9).

Ali, M.(2018). Meningkatkan Pembelajaran Chest pass Melalui Media Simpai dalam Permainan Bola Bakset Siswa Kelas XIIPS SMA Negeri 1 KUOK Tahun Ajaran 2016/2017. Jurnal Pendidikan Tambusai, 2(4), 533-544

Husdarta. (2011). Psikologi Olahraga. Bandung: Alfabeta.

Iqroni, D. (2017). Model Tes Keterampilan Dasar Dan Kondisi Fisik Untuk Mengidentifikasi Bakat Calon Atlet BolaBasket. Jurnal Keolahragaan, $5(2), 142-150$.

Junaidi, I. A. (2018). Peningkatan KeterampiIan Chest Pass BoIa Basket MeIaIui Metode Peer Teaching Mahasiswa Program Studi Pendidikan OIahraga. Penjaskesrek JournaI, 5(1), 37-44.

MeirizaI, Y., \& Rusmana, R. (2018). Perbandingan Iatihan PuII Up dan Iatihan Push Up Terhadap KeterampiIan Chest Pass BoIa Basket. JurnaI KepeIatihan OIahraga, 10(1), 26-33.

Nopiyanto, Y. E., \& Raibowo, S. (2020). Penerapan model pembelajaran Jigsaw untuk meningkatkan motivasi dan hasil belajar mahasiswa penjas pada mata kuliah filsafat penjas dan olahraga. Journal Of Sport Education (JOPE), 2(2), 61-69.

Nopiyanto, Y. E., Dimyati, D., \& Dongoran, F. (2019). Karakteristik Psikologis Atlet Sea Games Indonesia Ditinjau Dari Cabang Olahraga Tim. Sporta Saintika, 4(2), 27-46.

Pamuji, R. (2013). Pengaruh Gaya Mengejar Komando Dan Gaya Mengajar Resiprokal Terhadap Hasil Belajar Chest pass Dalam Permainan Bola Basket. PEDAGOGIK (JURNAL PENDIDIKAN SEKOLAH DASAR), 1(1), 24-33.

PB.PERBASI (2008). Official Basketball Rules, Jakarta : Bidang III PERBASI.

Raibowo, S., \& Nopiyanto, Y. E. (2020). Evaluasi Pembelajaran Pendidikan Jasmani Olahraga \& Kesehatan pada SMP Negeri Se-Kabupaten Mukomuko melalui Pendekatan Model Context, Input, Process \& Product (CIPP). Jurnal Pendidikan Kesehatan Rekreasi, 6(2), 146-165.

Strand, Bradford N. \& Wilson, Rolayne. (1993). Assessing Sport Skills. USA: Human Kinetics Publishers. 
Veri Rahmat Utama, Dian Pujianto, Ari Sutisyana

Pengaruh Latihan Passing Menggunakan Media Ban Bekas Terhadap Ketepatan Chest pass Pada

Team Pra Poprov Kabupaten Kepahiang

Sugiyono.(2012). Metode Penelitian Pendidikan (Pendekatan Kuatitatif, KuaIitatif, dan R\&D. Bandung: AIfabeta.

Yarmani, Y. (2017). Pengaruh Latihan Shooting Drills Terhadap Hasil Three Point Shooting Atlet Putra Klub Bola Basket King Spark Kota Bengkulu. Kinestetik: Jurnal Ilmiah Pendidikan Jasmani, 1(2), 75-79. 